\title{
Empagliflozin and Progression of Kidney Disease in Type 2 Diabetes
}

\author{
Christoph Wanner, M.D., Silvio E. Inzucchi, M.D., John M. Lachin, Sc.D., \\ David Fitchett, M.D., Maximilian von Eynatten, M.D., \\ Michaela Mattheus, Dipl. Biomath., Odd Erik Johansen, M.D., Ph.D., \\ Hans J. Woerle, M.D., Uli C. Broedl, M.D., and Bernard Zinman, M.D., \\ for the EMPA-REG OUTCOME Investigators*
}

A BSTRACT

\section{BACKGROUND}

Diabetes confers an increased risk of adverse cardiovascular and renal events. In the EMPA-REG OUTCOME trial, empagliflozin, a sodium-glucose cotransporter 2 inhibitor, reduced the risk of major adverse cardiovascular events in patients with type 2 diabetes at high risk for cardiovascular events. We wanted to determine the long-term renal effects of empagliflozin, an analysis that was a prespecified component of the secondary microvascular outcome of that trial.

\section{METHODS}

We randomly assigned patients with type 2 diabetes and an estimated glomerular filtration rate of at least $30 \mathrm{ml}$ per minute per $1.73 \mathrm{~m}^{2}$ of body-surface area to receive either empagliflozin (at a dose of $10 \mathrm{mg}$ or $25 \mathrm{mg}$ ) or placebo once daily. Prespecified renal outcomes included incident or worsening nephropathy (progression to macroalbuminuria, doubling of the serum creatinine level, initiation of renal-replacement therapy, or death from renal disease) and incident albuminuria.

\section{RESULTS}

Incident or worsening nephropathy occurred in 525 of 4124 patients $(12.7 \%)$ in the empagliflozin group and in 388 of 2061 (18.8\%) in the placebo group (hazard ratio in the empagliflozin group, 0.61 ; $95 \%$ confidence interval, 0.53 to 0.70 ; $\mathrm{P}<0.001)$. Doubling of the serum creatinine level occurred in 70 of 4645 patients $(1.5 \%)$ in the empagliflozin group and in 60 of 2323 (2.6\%) in the placebo group, a significant relative risk reduction of $44 \%$. Renal-replacement therapy was initiated in 13 of 4687 patients $(0.3 \%)$ in the empagliflozin group and in 14 of 2333 patients $(0.6 \%)$ in the placebo group, representing a $55 \%$ lower relative risk in the empagliflozin group. There was no significant between-group difference in the rate of incident albuminuria. The adverse-event profile of empagliflozin in patients with impaired kidney function at baseline was similar to that reported in the overall trial population.

\section{CONCLUSIONS}

In patients with type 2 diabetes at high cardiovascular risk, empagliflozin was associated with slower progression of kidney disease and lower rates of clinically relevant renal events than was placebo when added to standard care. (Funded by the Boehringer Ingelheim and Eli Lilly and Company Diabetes Alliance; EMPA-REG OUTCOME ClinicalTrials.gov number, NCT01131676.)
From the Department of Medicine, Division of Nephrology, Würzburg University Clinic, Würzburg (C.W.), and Boehringer Ingelheim Pharma, Ingelheim (M.E., M.M., H.J.W., U.C.B.) - both in Germany; the Section of Endocrinology, Yale University School of Medicine, New Haven, CT (S.E.I.); the Biostatistics Center, George Washington University, Rockville, MD (J.M.L.); the Divisions of Cardiology (D.F.) and Endocrinology (B.Z.), University of Toronto, and the LunenfeldTanenbaum Research Institute, Mount Sinai Hospital (B.Z.) - both in Toronto; and Boehringer Ingelheim Norway, Asker, Norway (O.E.J.). Address reprint requests to Dr. Wanner at the University Clinic, Oberdürrbacherstr. 6, D-97080 Würzburg, Germany, or atwanner_c@ukw.de.

*A complete list of investigators in the EMPA-REG OUTCOME trial is provided in the Supplementary Appendix, available at NEJM.org.

This article was published on June 14, 2016, at NEJM.org.

N Engl J Med 2016;375:323-34. DOI: 10.1056/NEJMoa1515920 Copyright (c) 2016 Massachusetts Medical Society. 
T YPE 2 DIABETES IS A MAJOR RISK FACTOR for macrovascular and microvascular disease. ${ }^{1}$ Kidney disease develops in approximately $35 \%$ of patients with type 2 diabetes $^{2}$ and is associated with increased mortality. ${ }^{3}$ Intensive glucose-lowering strategies have been shown to reduce surrogate markers of renal complications in patients with type 2 diabetes; however, evidence for improvement in advanced renal complications is limited..$^{4-8}$ Thus, despite optimized glucose control and the use of single-agent blockade of the renin-angiotensin-aldosterone system (RAAS), patients with type 2 diabetes remain at increased risk for death and complications from cardiorenal causes. ${ }^{9,10}$

Empagliflozin, a selective sodium-glucose cotransporter 2 inhibitor, reduces hyperglycemia in patients with type 2 diabetes by reducing the renal reabsorption of glucose, thereby increasing urinary glucose excretion. ${ }^{11}$ The use of empagliflozin has been associated with a lowering of glycated hemoglobin levels in patients with type 2 diabetes, including those with stage 2 or 3a chronic kidney disease, and with reductions in weight and blood pressure, without increases in heart rate. ${ }^{12-19}$ Empagliflozin has been shown to reduce intraglomerular pressure and improve hyperfiltration in patients with type 1 diabetes, ${ }^{20,21}$ and it has been suggested that these effects may translate into improved renal outcomes. ${ }^{22}$ However, concern has been raised that sodium-glucose cotransporter 2 inhibitors may be associated with long-term adverse renal effects.

In the recent EMPA-REG OUTCOME trial, ${ }^{23}$ the primary goal was to assess cardiovascular outcomes. Here we report the results of a prespecified secondary objective of that trial, which was to examine the effects of empagliflozin on microvascular outcomes and, in particular, progression of kidney disease in patients with type 2 diabetes at high risk for cardiovascular events.

\section{METHODS}

TRIAL DESIGN AND OVERSIGHT

The design and methods of the EMPA-REG OUTCOME trial have been described previously. ${ }^{24}$ In addition, the trial protocol is available with the full text of this article at NEJM.org. Briefly, the study population included patients who had type 2 diabetes, established cardiovascular disease, and an estimated glomerular filtration rate (eGFR) of at least $30 \mathrm{ml}$ per minute per
$1.73 \mathrm{~m}^{2}$ of body-surface area, according to the four-variable Modification of Diet in Renal Disease (MDRD) formula. Patients were randomly assigned to receive either empagliflozin (at a dose of $10 \mathrm{mg}$ or $25 \mathrm{mg}$ ) or placebo once daily in addition to standard care.

All the authors were involved in the trial design and had access to the data, which were gathered and analyzed by Boehringer Ingelheim, one of the trial sponsors. Medical writing assistance was provided by FleishmanHillard Fishburn, with funding from Boehringer Ingelheim. All the authors vouch for the accuracy and completeness of the data analyses and for the fidelity of the trial to the protocol. The first and fifth authors wrote the first draft of the manuscript. All the authors submitted revisions and made the decision to submit the manuscript for publication.

\section{PRIMARY AND KEY SECONDARY CARDIOVASCULAR OUTCOMES}

The primary outcome of the EMPA-REG OUTCOME trial was a composite of three major adverse cardiovascular events (3-point MACE), which was defined as the first occurrence of death from cardiovascular causes, nonfatal myocardial infarction, or nonfatal stroke. The key secondary outcome was a composite of the primary outcome plus hospitalization for unstable angina (4-point MACE).

\section{MICROVASCULAR AND RENAL OUTCOMES}

A secondary outcome of the EMPA-REG OUTCOME trial was a composite microvascular outcome that included the first occurrence of any of the following: the initiation of retinal photocoagulation, vitreous hemorrhage, diabetes-related blindness, or incident or worsening nephropathy. In this report, we focus on the results of the renal microvascular outcomes, as prespecified in the statistical analysis plan (available at NEJM.org). The first renal microvascular outcome was incident or worsening nephropathy, defined as progression to macroalbuminuria (urinary albuminto-creatinine ratio, $>300 \mathrm{mg}$ of albumin per gram of creatinine); a doubling of the serum creatinine level, accompanied by an eGFR of $\leq 45 \mathrm{ml}$ per minute per $1.73 \mathrm{~m}^{2}$, as calculated by the MDRD formula; the initiation of renal-replacement therapy; or death from renal disease. Other prespecified renal microvascular outcomes were a composite of incident or worsening nephropathy or death from cardiovascular causes, 
the individual components of incident or worsening nephropathy, and incident albuminuria (urinary albumin-to-creatinine ratio, $\geq 30$ ) in patients with a normal albumin level (urinary albumin-to-creatinine ratio, <30) at baseline.

We conducted post hoc analyses in a subgroup of patients with prevalent kidney disease (defined as an eGFR of $59 \mathrm{ml}$ per minute per $1.73 \mathrm{~m}^{2}$ or less, as calculated by the MDRD formula, or macroalbuminuria) at baseline. In addition, we performed post hoc analyses of a composite of a doubling of the serum creatinine level, the initiation of renal-replacement therapy, or death from renal disease.

\section{SAFETY AND LABORATORY ASSESSMENTS}

We performed assessments of safety and adverseevent profiles, as described previously. ${ }^{24} \mathrm{We}$ evaluated the incidence of acute renal failure using the narrow standardized Medical Dictionary for Regulatory Activities (MedDRA) query, which included the preferred term acute kidney injury. We also evaluated the incidence of hyperkalemia using two MedDRA preferred terms (hyperkalemia and increased blood potassium). Serum creatinine and urinary albumin in spot urine samples obtained during regular study visits were measured in central laboratories with the use of standardized procedures. Events that were consistent with changes in the albuminuria category were captured if any laboratory assessment during the trial fulfilled the given criteria on one occasion. We used the MDRD formula to assess the eGFR at baseline. ${ }^{25}$ For prespecified assessments of renal function over time, we used the creatinine equation developed by the Chronic Kidney Disease Epidemiology Collaboration (CKD-EPI). ${ }^{26}$

\section{STATISTICAL ANALYSIS}

We used a modified intention-to-treat approach to perform analyses in patients who had received at least one dose of a study drug. All analyses were performed at the nominal alpha level of 0.05 without correction for multiple hypothesis testing. No formal power calculations were performed a priori for microvascular outcomes. The trial protocol specified that the outcomes of incident or worsening nephropathy (and incident or worsening nephropathy or cardiovascular death) would be analyzed in treated patients who did not have macroalbuminuria at baseline, who had available measurements of serum creatinine at baseline and after baseline, and who had postbaseline measurements of the urinary albumin-to-creatinine ratio (unless patients who did not fulfill these criteria had at least one of the other components of the composite renal outcome). A post hoc sensitivity analysis included all treated patients. Data from patients who did not have an event were censored on the last day they were known to be free of the outcome.

We used a Cox proportional-hazards model to assess between-group differences in the risk of an outcome after adjustment for study group, age, sex, baseline body-mass index, baseline glycated hemoglobin level, baseline eGFR, and region. We also performed subgroup analyses that included additional factors for subgroup and for interaction between the study group and subgroup. Prespecified analyses included comparisons of the pooled empagliflozin doses $(10 \mathrm{mg}$ and $25 \mathrm{mg}$ ) and the individual doses versus placebo. A mixed-model, repeated-measures analysis was used to evaluate changes in the eGFR over time and included the glycated hemoglobin level and eGFR (according to CKD-EPI criteria) at baseline as linear covariates and region, baseline body-mass index, the last week a patient could have had an eGFR measurement, study group, visit, interaction between visit and study group, interaction between the baseline glycated hemoglobin level and visit, and interaction between the baseline eGFR and visit as fixed effects. We used a random-intercept and time-coefficient model to assess differences between the study groups in the average rate of change in the eGFR for prespecified time periods, with study group, baseline body-mass index, and region as fixed classification effects and baseline glycated hemoglobin level, time, and interaction between the study group and time as linear covariates. Intercepts and slopes over time were allowed to vary randomly between patients by including the patient and time as random effects.

RESULTS

\section{PATIENTS}

A total of 7020 patients at 590 sites in 42 countries received at least one dose of a study drug. According to the trial design, more than $99 \%$ of the patients had established cardiovascular disease. At baseline, the eGFR was 45 to $59 \mathrm{ml}$ per minute per $1.73 \mathrm{~m}^{2}$ in $17.8 \%$ of the patients and 
30 to $44 \mathrm{ml}$ per minute per $1.73 \mathrm{~m}^{2}$ in $7.7 \%$; $28.7 \%$ had microalbuminuria, and $11.0 \%$ had macroalbuminuria. In total, $80.7 \%$ of the patients were taking angiotensin-converting-enzyme inhibitors or angiotensin-receptor blockers at baseline. The patients were categorized according to whether the eGFR was $60 \mathrm{ml}$ per minute per $1.73 \mathrm{~m}^{2}$ or more or $59 \mathrm{ml}$ per minute per $1.73 \mathrm{~m}^{2}$ or less at baseline. The baseline characteristics of the patients were generally similar in the two study groups (Table 1; and Table S1 in the Supplementary Appendix, available at NEJM.org). A higher percentage of patients in the placebo group received additional cardiovascular medications during the trial (Table S2 in the Supplementary Appendix). The median duration of treatment was 2.6 years, and the median observation time was 3.1 years.

\section{CARDIOVASCULAR OUTCOMES}

The primary outcome that was reported previously showed a significantly lower risk of 3-point MACE in the pooled empagliflozin group than in the placebo group, a difference that was driven by a lower rate of death from cardiovascular causes. ${ }^{23}$ Prespecified secondary and additional cardiovascular outcomes that were reported previously included the 4-point MACE (and components of this composite outcome), hospitalization for heart failure, and death from any cause. ${ }^{23}$

\section{MICROVASCULAR OUTCOME}

The prespecified composite microvascular outcome in the overall trial population occurred in 577 of 4132 patients (14.0\%) in the empagliflozin group and in 424 of 2068 patients (20.5\%) in the placebo group, a significant relative risk reduction of $38 \%$ (Table S3 in the Supplementary Appendix). Because the overall result for this composite microvascular outcome was driven entirely by the renal component, we have focused on renal outcomes in this report.

\section{RENAL OUTCOMES}

An assessment of renal outcomes was a prespecified objective of the trial, and outcomes were defined in a secondary statistical analysis plan. Incident or worsening nephropathy occurred in 525 of 4124 patients (12.7\%) in the empagliflozin group and in 388 of 2061 patients $(18.8 \%)$ in the placebo group, a significant relative risk reduction of 39\% (Fig. 1A and Fig. 2). A consistent benefit of empagliflozin was seen across prespecified subgroups (Fig. S1 in the Supplementary Appendix) and across the two doses of empagliflozin (Fig. S2 in the Supplementary Appendix).

The composite outcome of incident or worsening nephropathy or cardiovascular death was significantly lower in the empagliflozin group than in the placebo group (Fig. 2, and Fig. S3A in the Supplementary Appendix). Equivalent results were seen across the two doses of empagliflozin (Fig. S3B in the Supplementary Appendix).

Progression to macroalbuminuria occurred in 459 of 4091 patients (11.2\%) in the empagliflozin group and in 330 of 2033 (16.2\%) in the placebo group, a significant relative risk reduction of 38\% (Fig. 2). A doubling of the serum creatinine level occurred in 70 of 4645 patients (1.5\%) in the empagliflozin group and in 60 of $2323(2.6 \%)$ in the placebo group, a significant relative risk reduction of $44 \%$. The initiation of renal-replacement therapy occurred in 13 of 4687 patients $(0.3 \%)$ in the empagliflozin group and in 14 of $2333(0.6 \%)$ in the placebo group, a significant relative risk reduction of $55 \%$. There were three deaths from renal disease in the empagliflozin group $(0.1 \%)$ and none in the placebo group. There was no significant between-group difference in the rate of incident albuminuria, which occurred in 1430 of 2779 patients (51.5\%) in the empagliflozin group and in 703 of 1374 $(51.2 \%)$ in the placebo group (Fig. 2).

\section{POST HOC ASSESSMENTS OF RENAL OUTCOMES}

Results for the composite renal outcomes were validated in a post hoc sensitivity analysis (Table S4 in the Supplementary Appendix) and in a subgroup analysis of patients with prevalent kidney disease at baseline (Table S5 and Fig. S4 in the Supplementary Appendix). The effect of empagliflozin was consistent in further analyses in which progression to macroalbuminuria was excluded from the composite renal outcome (Fig. 1B and Fig. 2) with no heterogeneity among subgroups of patients with a normal albumin level or microalbuminuria or macroalbuminuria at baseline and in subgroups according to the eGFR at baseline (Figs. S5 and S6 in the Supplementary Appendix).

\section{RENAL FUNCTION OVER TIME}

Renal function over time, as measured by the eGFR, is shown in Fig. 3A. Similar patterns in 
Table 1. Characteristics of the Patients at Baseline, According to the Estimated Glomerular Filtration Rate (eGFR).*

\begin{tabular}{|c|c|c|c|c|}
\hline \multirow[t]{2}{*}{ Characteristic } & \multicolumn{2}{|c|}{$\begin{array}{l}\text { Patients with eGFR of } 59 \mathrm{ml} \text { per } \\
\text { Minute per } 1.73 \mathrm{~m}^{2} \text { or Less }\end{array}$} & \multicolumn{2}{|c|}{$\begin{array}{l}\text { Patients with eGFR of } 60 \mathrm{ml} \text { per } \\
\text { Minute per } 1.73 \mathrm{~m}^{2} \text { or More }\end{array}$} \\
\hline & $\begin{array}{l}\text { Placebo } \\
(\mathrm{N}=607)\end{array}$ & $\begin{array}{l}\text { Empagliflozin } \\
\quad(\mathrm{N}=1212)\end{array}$ & $\begin{array}{c}\text { Placebo } \\
(\mathrm{N}=1726)\end{array}$ & $\begin{array}{l}\text { Empagliflozin } \\
\qquad(\mathrm{N}=3473)\end{array}$ \\
\hline Age $-y r$ & $67.1 \pm 8.2$ & $67.1 \pm 7.6$ & $61.9 \pm 8.6$ & $61.7 \pm 8.5$ \\
\hline Male sex - no. (\%) & $418(68.9)$ & $816(67.3)$ & $1262(73.1)$ & $2518(72.5)$ \\
\hline Body-mass index广 & $30.9 \pm 5.4$ & $31.0 \pm 5.5$ & $30.6 \pm 5.2$ & $30.5 \pm 5.2$ \\
\hline Glycated hemoglobin - \% & $8.03 \pm 0.85$ & $8.07 \pm 0.86$ & $8.10 \pm 0.84$ & $8.07 \pm 0.84$ \\
\hline Interval of >10 yr since diagnosis of type 2 diabetes - no. (\%) & $422(69.5)$ & $794(65.5)$ & $917(53.1)$ & $1876(54.0)$ \\
\hline \multicolumn{5}{|l|}{ Blood pressure $-\mathrm{mm} \mathrm{Hg}$} \\
\hline Systolic & $136.4 \pm 18.7$ & $136.1 \pm 18.0$ & $135.6 \pm 16.7$ & $135.0 \pm 16.6$ \\
\hline Diastolic & $74.6 \pm 10.3$ & $74.5 \pm 9.9$ & $77.6 \pm 10.0$ & $77.4 \pm 9.5$ \\
\hline Estimated glomerular filtration rate $-\mathrm{ml} / \mathrm{min} / 1.73 \mathrm{~m}^{2}$ & $48.6 \pm 7.8$ & $48.4 \pm 8.2$ & $82.7 \pm 16.6$ & $83.1 \pm 17.1$ \\
\hline \multicolumn{5}{|l|}{ Urinary albumin-to-creatinine ratio — no. (\%)』 } \\
\hline$<30$ & $283(46.6)$ & $566(46.7)$ & $1099(63.7)$ & $2223(64.0)$ \\
\hline 30 to 300 & $205(33.8)$ & $411(33.9)$ & $470(27.2)$ & $926(26.7)$ \\
\hline$>300$ & $115(18.9)$ & $223(18.4)$ & $145(8.4)$ & $286(8.2)$ \\
\hline \multicolumn{5}{|l|}{ Cholesterol $-\mathrm{mg} / \mathrm{dl}$} \\
\hline Low-density lipoprotein & $85.0 \pm 36.1$ & $84.4 \pm 35.8$ & $84.8 \pm 35.1$ & $86.5 \pm 36.0$ \\
\hline High-density lipoprotein $\|$ & $42.9 \pm 10.7$ & $44.2 \pm 12.5$ & $44.4 \pm 11.5$ & $44.7 \pm 11.7$ \\
\hline Triglycerides - mg/dI\| & $180.4 \pm 107.4$ & $173.5 \pm 108.1$ & $167.2 \pm 125.6$ & $169.4 \pm 136.4$ \\
\hline Coronary artery disease & $482(79.4)$ & $938(77.4)$ & $1281(74.2)$ & $2606(75.0)$ \\
\hline History of stroke*** & $156(25.7)$ & $293(24.2)$ & $397(23.0)$ & $791(22.8)$ \\
\hline Peripheral artery disease $† \dagger$ & $130(21.4)$ & $314(25.9)$ & $349(20.2)$ & $667(19.2)$ \\
\hline Cardiac failuretr & $89(14.7)$ & $174(14.4)$ & $155(9.0)$ & $288(8.3)$ \\
\hline \multicolumn{5}{|l|}{ Concomitant medication — no. (\%) } \\
\hline $\begin{array}{l}\text { Angiotensin-converting-enzyme inhibitor or angiotensin- } \\
\text { receptor blocker }\end{array}$ & $502(82.7)$ & $1031(85.1)$ & $1366(79.1)$ & $2766(79.6)$ \\
\hline Beta-blocker & $415(68.4)$ & $829(68.4)$ & $1083(62.7)$ & $2226(64.1)$ \\
\hline Diuretic & $355(58.5)$ & $710(58.6)$ & $633(36.7)$ & $1336(38.5)$ \\
\hline Calcium-channel blocker & $227(37.4)$ & $446(36.8)$ & $561(32.5)$ & $1082(31.2)$ \\
\hline Statin & 461 (75.9) & 966 (79.7) & $1312(76.0)$ & $2663(76.7)$ \\
\hline Aspirin & $495(81.5)$ & $981(80.9)$ & $1432(83.0)$ & $2894(83.3)$ \\
\hline Metformin & $369(60.8)$ & 711 (58.7) & $1365(79.1)$ & $2746(79.1)$ \\
\hline Sulfonylurea & $234(38.6)$ & $480(39.6)$ & 758 (43.9) & $1534(44.2)$ \\
\hline Insulin & $357(58.8)$ & 699 (57.7) & $778(45.1)$ & 1551 (44.7) \\
\hline
\end{tabular}

* Plus-minus values are means \pm SD. The GFR at baseline was estimated according to the four-variable Modification of Diet in Renal Disease formula. Data on eGFR at baseline were not available for two patients in the empagliflozin group. There were no significant differences between the study groups except with respect to high-density lipoprotein cholesterol $(P=0.02)$ and peripheral artery disease $(P=0.04)$ in patients with an eGFR of $59 \mathrm{ml}$ per minute per $1.73 \mathrm{~m}^{2}$ or less. To convert the values for cholesterol to millimoles per liter, multiply by 0.02586 . To convert the values for triglycerides to millimoles per liter, multiply by 0.01129 .

$\dagger$ The body-mass index is the weight in kilograms divided by the square of the height in meters.

+ The glycated hemoglobin value was missing for one patient in the empagliflozin group in patients with an eGFR of $60 \mathrm{ml}$ per minute per $1.73 \mathrm{~m}^{2}$ or more.

$\int$ This ratio was measured in milligrams of albumin per grams of creatinine.

I Low-density lipoprotein cholesterol was measured in 598 patients in the placebo group and 1201 in the empagliflozin group in patients with an eGFR of $59 \mathrm{ml}$ per minute per $1.73 \mathrm{~m}^{2}$ or less and in 1711 patients in the placebo group and 3421 in the empagliflozin group in patients with an eGFR of $60 \mathrm{ml}$ per minute per $1.73 \mathrm{~m}^{2}$ or more.

|| High-density lipoprotein cholesterol and triglycerides were measured in 598 patients in the placebo group and 1202 in the empagliflozin group in patients with an eGFR of $59 \mathrm{ml}$ per minute per $1.73 \mathrm{~m}^{2}$ or less and in 1711 patients in the placebo group and 3423 in the empagliflozin group in patients with an eGFR of $60 \mathrm{ml}$ per minute per $1.73 \mathrm{~m}^{2}$ or more.

$* *$ Information on stroke history was not available for one patient in the placebo group in patients with an eGFR of $60 \mathrm{ml}$ per minute per $1.73 \mathrm{~m}^{2}$ or more.

$\dagger \dagger$ Information on peripheral artery disease was not available for one patient in the placebo group and one patient in the empagliflozin group in patients with an eGFR of $60 \mathrm{ml}$ per minute per $1.73 \mathrm{~m} 2$ or more.

+ Cardiac failure was determined according to the narrow standardized Medical Dictionary for Regulatory Activities query for the condition. 
the eGFR were observed in patients with an eGFR of $60 \mathrm{ml}$ per minute per $1.73 \mathrm{~m}^{2}$ or more and in patients with an eGFR of $59 \mathrm{ml}$ per minute per $1.73 \mathrm{~m}^{2}$ or less at baseline (Fig. S7 in the Supplementary Appendix). The initial decrease in the eGFR in the empagliflozin group was completely reversed after the cessation of the study drug (Fig. 3B). At the follow-up visit, the adjusted mean difference from placebo in the change from baseline in the eGFR with each of the two doses of empagliflozin was $4.7 \mathrm{ml}$ per minute per $1.73 \mathrm{~m}^{2}$ (95\% confidence interval, 4.0 to 5.5 ; $\mathrm{P}<0.001$ for both comparisons) (Fig. $3 \mathrm{~B}$ ).

We quantified the difference between the study groups in the average rate of change in the eGFR for three prespecified time periods, using the CKD-EPI creatinine equation. From baseline to week 4 (period 1), there was a short-term decrease in the eGFR in the empagliflozin groups, with mean $( \pm S E)$ adjusted estimates of weekly decreases of $0.62 \pm 0.04 \mathrm{ml}$ per minute per $1.73 \mathrm{~m}^{2}$ in the 10-mg group and $0.82 \pm 0.04 \mathrm{ml}$ per minute per $1.73 \mathrm{~m}^{2}$ in the $25-\mathrm{mg}$ group, as compared with a small increase (of $0.01 \pm 0.04 \mathrm{ml}$ per minute per $\left.1.73 \mathrm{~m}^{2}\right)$ in the placebo group $(\mathrm{P}<0.001$ for both comparisons with placebo). Thereafter, during long-term administration (period 2; from week 4 to the last week of treatment), the eGFR remained stable in the empagliflozin groups and declined steadily in the placebo group, with adjusted estimates of annual decreases of $0.19 \pm 0.11$ $\mathrm{ml}$ per minute per $1.73 \mathrm{~m}^{2}$ in the $10-\mathrm{mg}$ and 25-mg empagliflozin groups, as compared with a decrease of $1.67 \pm 0.13 \mathrm{ml}$ per minute per $1.73 \mathrm{~m}^{2}$ in the placebo group ( $\mathrm{P}<0.001$ for both comparisons with placebo). After the cessation of the study drug (period 3; last week of treatment to follow-up), the eGFR increased with both doses of empagliflozin, with adjusted estimates for weekly increases of $0.48 \pm 0.04 \mathrm{ml}$ per minute per $1.73 \mathrm{~m}^{2}$ in the 10 -mg group and $0.55 \pm 0.04$ $\mathrm{ml}$ per minute per $1.73 \mathrm{~m}^{2}$ in the $25-\mathrm{mg}$ group, as compared with a small decrease (of $0.04 \pm 0.04$ $\mathrm{ml}$ per minute per $1.73 \mathrm{~m}^{2}$ ) in the placebo group ( $\mathrm{P}<0.001$ for both comparisons with placebo).

\section{SAFETY AND ADVERSE EVENTS}

The percentages of patients who had an adverse event, a serious adverse event, or an adverse event leading to study-drug discontinuation were similar in the empagliflozin group and the placebo group in patients with an eGFR of $60 \mathrm{ml}$ per minute per $1.73 \mathrm{~m}^{2}$ or more and in patients with an eGFR of $59 \mathrm{ml}$ per minute per $1.73 \mathrm{~m}^{2}$ or less (Table 2, and Table S6 and Fig. S8 in the Supplementary Appendix). Genital infections were reported in a higher percentage of patients in the empagliflozin group than in the placebo group. There were similar rates of overall urinary tract infection, complicated urinary tract infection, and pyelonephritis in the two study groups. Urosepsis was reported infrequently, but the proportion of patients with events was higher with empagliflozin than with placebo (Table S7 in the Supplementary Appendix). The percentages of patients with confirmed hypoglycemic episodes, diabetic ketoacidosis, thromboembolic events, bone fractures, and events consistent with volume depletion were similar in the two study groups. Events that were consistent with acute renal failure, including acute kidney injury, and hyperkalemia were reported in a lower percentage of patients in the empagliflozin group than in the placebo group (Figs. S8 and S9 in the Supplementary Appendix). Clinical laboratory measurements are provided in Table S8 in the Supplementary Appendix.

\section{DISCUSSION}

In patients with type 2 diabetes at high risk for cardiovascular events, those who received empagliflozin in addition to standard care had a significantly lower risk of microvascular outcome events than did those receiving placebo, a difference that was driven by a lower risk of progression of kidney disease (as defined by incident or worsening nephropathy). Patients in the empagliflozin group also had a significantly lower risk of progression to macroalbuminuria or clinically relevant renal outcomes, such as a doubling of the serum creatinine level and initiation of renal-replacement therapy, than did those in the placebo group.

The magnitude of the renal effect associated with empagliflozin was consistent with respect to the competing risk of death from cardiovascular causes, as well as between empagliflozin doses of $10 \mathrm{mg}$ and $25 \mathrm{mg}$ and across prespecified subgroups, including patients with prevalent kidney disease. These results were observed in a population of patients whose blood pressure was well managed, with extensive use of RAAS blockers, the recommended treatment for kidney 
disease in patients with type 2 diabetes. However, the renal effects of empagliflozin cannot necessarily be generalized to patients with type 2 diabetes at lower cardiovascular risk. Generalization of the findings to black patients also has limitations because of the small sample size that we studied. Further clinical research is warranted to validate our findings in broader populations at risk for adverse renal outcomes.

Empagliflozin was associated with lower rates of hyperglycemia and lower values for weight and blood pressure than was placebo. ${ }^{23} \mathrm{~A}$ trial comparing an intensive multifactorial intervention with conventional therapy in patients with type 2 diabetes and microalbuminuria did not show significant differences in the decline in renal function after 7.8 years. ${ }^{27}$ Thus, in our trial, the magnitude of the observed effect on these risk factors over a median follow-up period of 3.1 years is unlikely to fully account for the observed difference in renal function among patients receiving empagliflozin.

The mechanisms behind the renal effects of empagliflozin are probably multifactorial, but direct renovascular effects may play an important role. ${ }^{21,28,29}$ Empagliflozin reduces proximal tubular sodium reabsorption, thereby increasing distal sodium delivery to the macula densa, which has been shown to activate tubuloglomerular feedback, leading to afferent vasomodulation and a decrease in hyperfiltration. ${ }^{30}$ In patients with type 1 diabetes and hyperfiltration, empagliflozin reduces the intraglomerular pressure. ${ }^{20}$ Despite the low-pressure environment of renal glomeruli, a reduction in glomerular hypertension of approximately 6 to $8 \mathrm{~mm} \mathrm{Hg}$ was observed with empagliflozin. ${ }^{20}$ Other effects, such as those on arterial stiffness, ${ }^{28,29}$ vascular resistance, ${ }^{28}$ serum uric acid levels, ${ }^{23}$ and the systemic and renal neurohormonal systems, ${ }^{29,31,32}$ may also contribute to the improvements in the progression of renal disease observed with empagliflozin. Further research is needed to explore whether empagliflozin-associated changes in blood volume or renal perfusion may alter serum creatinine turnover and renal-function assessments.

Previous trials have focused on the role of RAAS blockade for improving renal outcomes in type 2 diabetes. ${ }^{33-35}$ Such blockade causes vasodilation of the efferent arteriolar system of the glomerulus and a reduction in intraglomerular

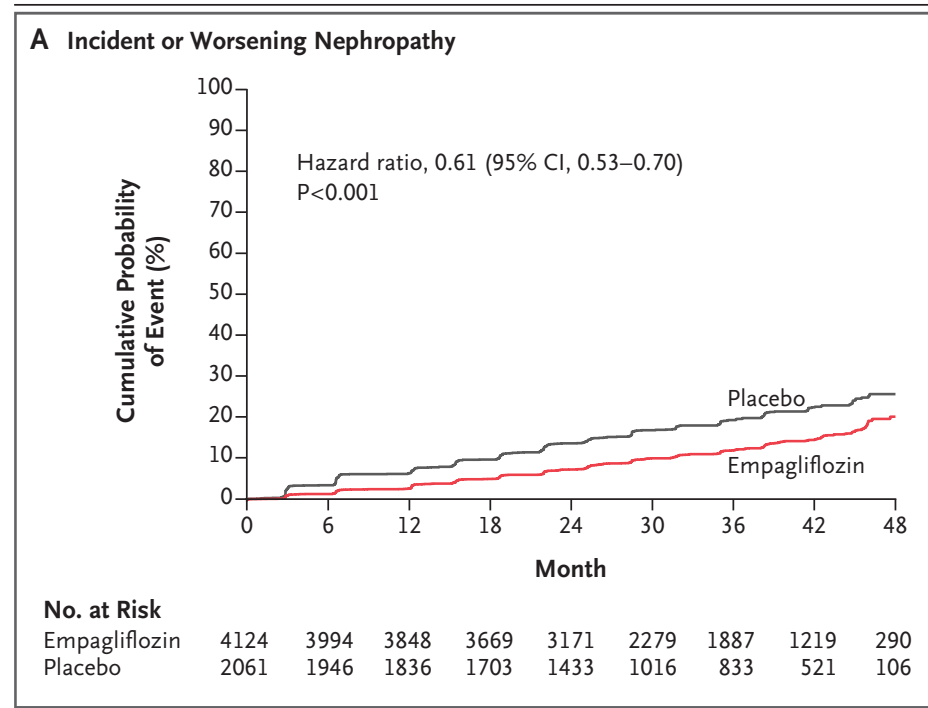

B Post Hoc Renal Composite Outcome

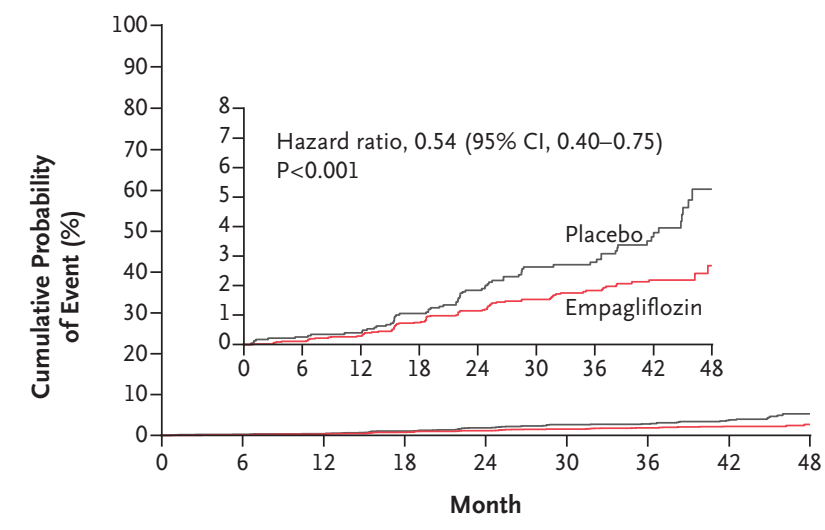

No. at Risk

$\begin{array}{llllllllll}\text { Empagliflozin } & 4645 & 4500 & 4377 & 4241 & 3729 & 2715 & 2280 & 1496 & 360\end{array}$ $\begin{array}{llllllllll}\text { Placebo } & 2323 & 2229 & 2146 & 2047 & 1771 & 1289 & 1079 & 680 & 144\end{array}$

Figure 1. Kaplan-Meier Analysis of Two Key Renal Outcomes.

Shown are estimates of the probability of a first occurrence of a prespecified renal composite outcome of incident or worsening nephropathy (Panel A) and of a post hoc renal composite outcome (a doubling of the serum creatinine level, the initiation of renal-replacement therapy, or death from renal disease) (Panel B) among patients who received at least one dose of either empagliflozin or placebo. The inset in Panel B shows the data on an expanded $y$ axis. Hazard ratios are based on Cox regression analyses. Because of the declining numbers of patients at risk, Kaplan-Meier curves have been truncated at 48 months.

pressure. ${ }^{36,37}$ This vasomodulatory mechanism is known to cause a short-term decrease in the eGFR, ${ }^{38}$ which is accompanied by a smaller decline in renal function during continued treatment. ${ }^{39}$ In our trial, empagliflozin showed a similar pattern of change in renal function (i.e., a short-term decrease followed by stabilization 


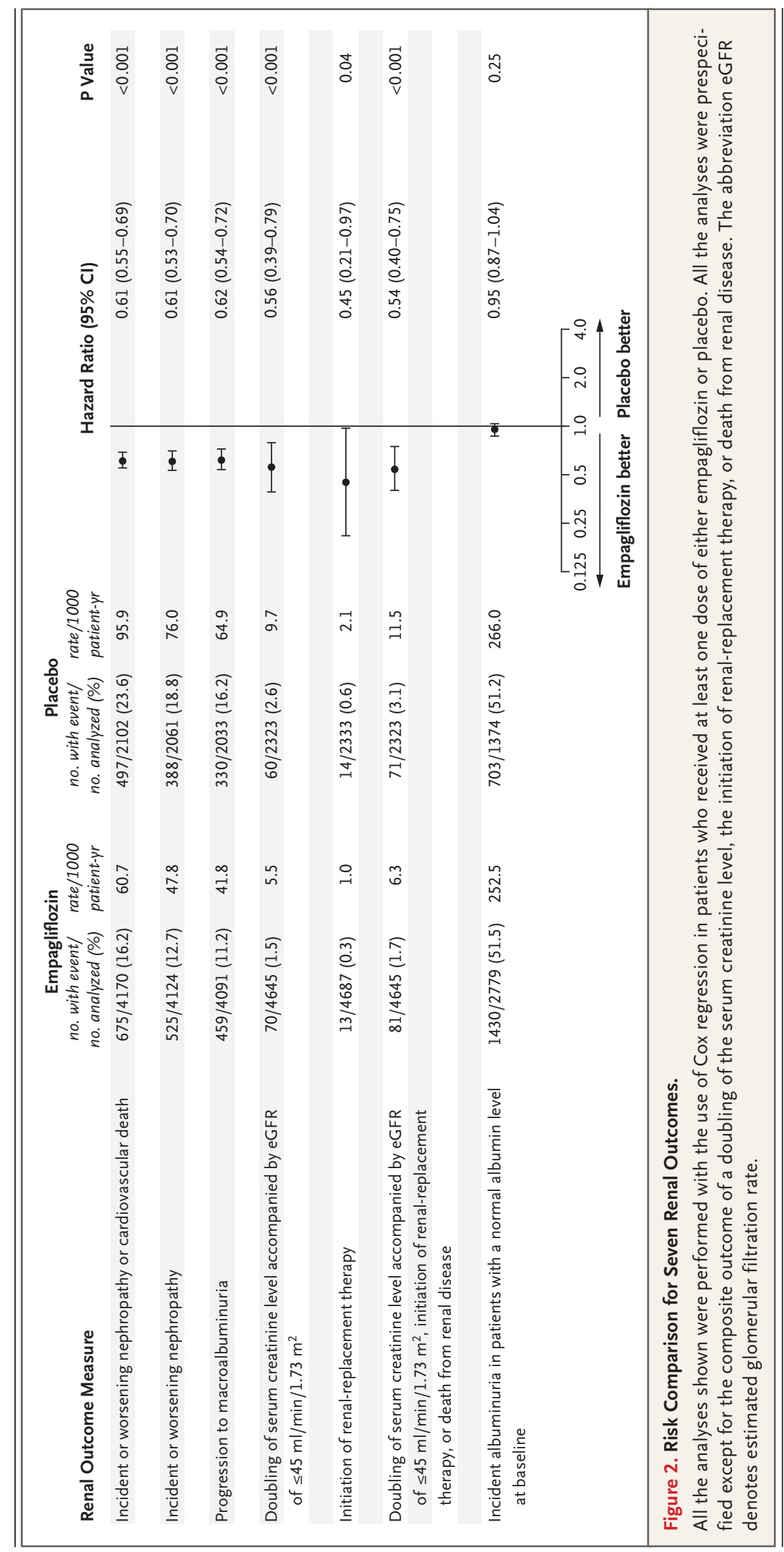




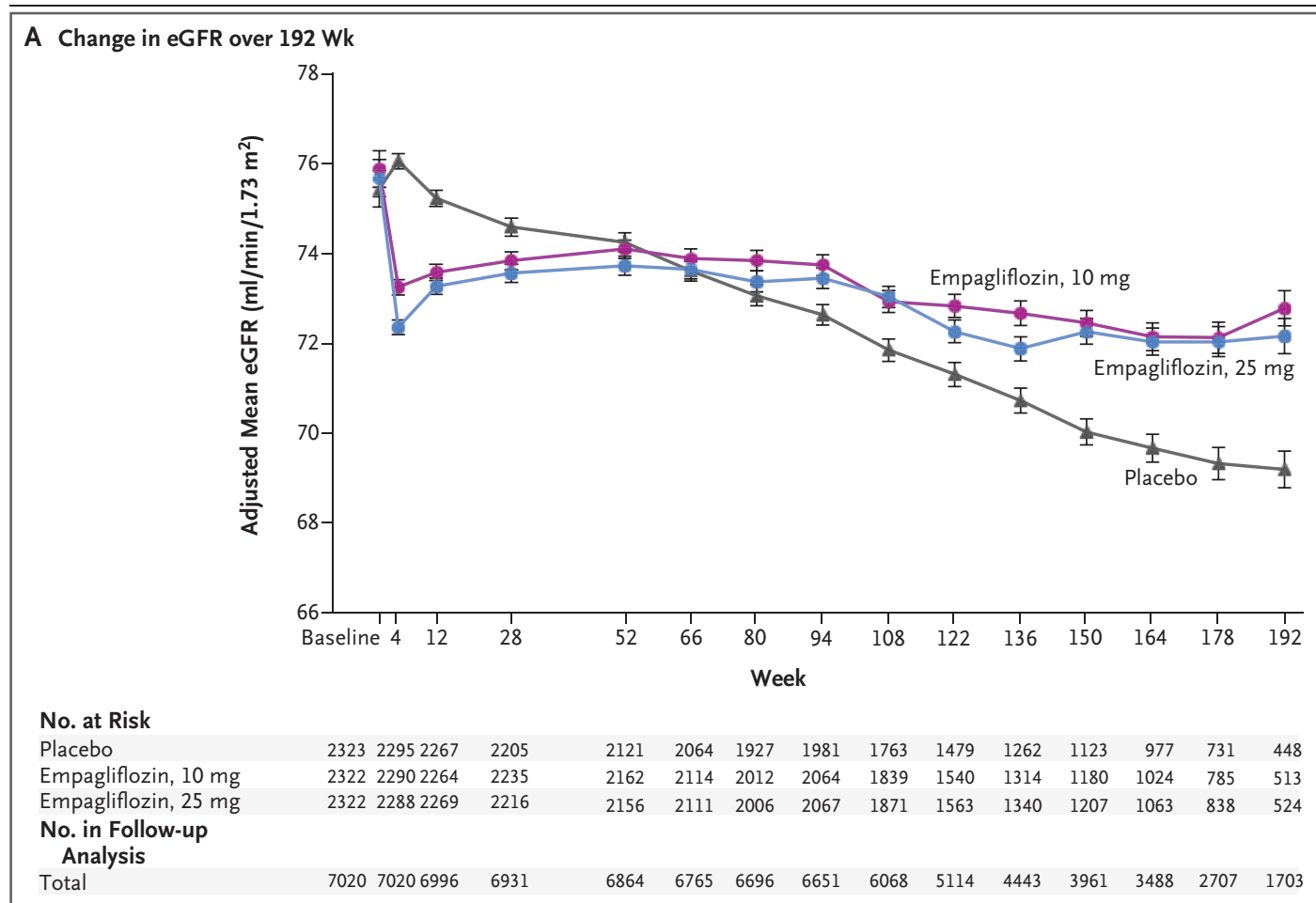

B Change in eGFR from Baseline to Last Measurement during Treatment and Follow-up

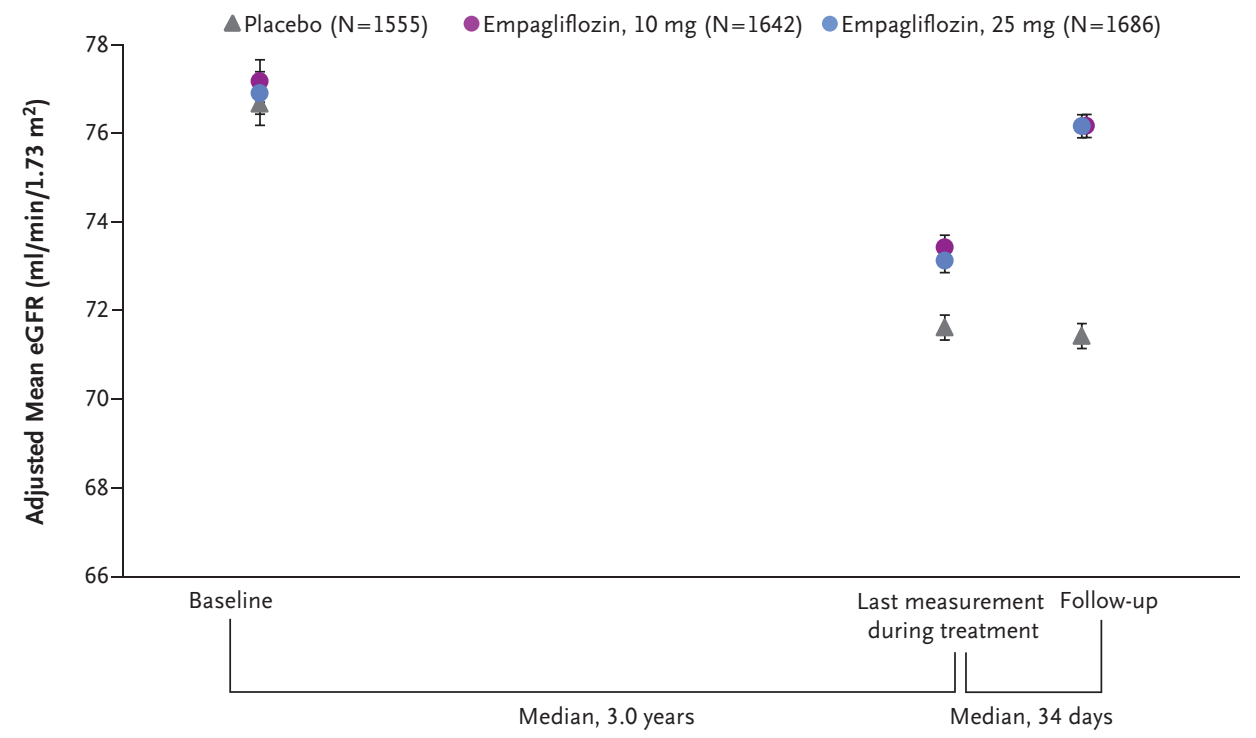

Figure 3. Renal Function over Time.

Shown are the adjusted means for the estimated glomerular filtration rate (eGFR) over a period of 192 weeks (Panel A) and at the last measurement during treatment and at follow-up (Panel B) among patients who received empagliflozin (at a dose of $10 \mathrm{mg}$ or $25 \mathrm{mg}$ ) or placebo. Baseline values are means, and the I bars indicate standard errors. The eGFR was calculated according to the creatinine formula developed by the Chronic Kidney Disease Epidemiology Collaboration. Among patients in the empagliflozin group, the adjusted mean difference from placebo in the change from baseline at follow-up (Panel B) was $4.7 \mathrm{ml}$ per minute per $1.73 \mathrm{~m}^{2}$ in both the $10-\mathrm{mg}$ and $25-\mathrm{mg}$ groups $(\mathrm{P}<0.001$ for both comparisons). Panel $A$ is based on prespecified mixed-model, repeated-measures analysis in patients who received at least one dose of a study drug and had a baseline and postbaseline measurement. Panel B is based on a prespecified analysis of a covariance model (with the baseline eGFR and glycated hemoglobin level as linear covariates and baseline body-mass index, region, and study group as fixed effects) in patients who underwent measurements at all three time points.

The New England Journal of Medicine 


\begin{tabular}{|c|c|c|c|c|c|c|c|c|}
\hline \multirow[t]{3}{*}{ Event } & \multicolumn{4}{|c|}{$\begin{array}{l}\text { Patients with Baseline eGFR of } 59 \mathrm{ml} \text { per Minute } \\
\text { per } 1.73 \mathrm{~m}^{2} \text { or Less }\end{array}$} & \multicolumn{4}{|c|}{$\begin{array}{l}\text { Patients with Baseline eGFR of } 60 \mathrm{ml} \text { per Minute } \\
\text { per } 1.73 \mathrm{~m}^{2} \text { or More }\end{array}$} \\
\hline & \multicolumn{2}{|c|}{$\begin{array}{l}\text { Placebo } \\
(\mathrm{N}=607)\end{array}$} & \multicolumn{2}{|c|}{$\begin{array}{l}\text { Empagliflozin } \\
\quad(\mathrm{N}=1212)\end{array}$} & \multicolumn{2}{|c|}{$\begin{array}{l}\text { Placebo } \\
(\mathrm{N}=1726)\end{array}$} & \multicolumn{2}{|c|}{$\begin{array}{l}\text { Empagliflozin } \\
\qquad(\mathrm{N}=3473)\end{array}$} \\
\hline & no. (\%) & $\begin{array}{l}\text { rate per } 100 \\
\text { patient- } y \text { r }\end{array}$ & no. (\%) & $\begin{array}{l}\text { rate per } 100 \\
\text { patient-yr }\end{array}$ & no. (\%) & $\begin{array}{l}\text { rate per } 100 \\
\text { patient- } y r\end{array}$ & nо. (\%) & $\begin{array}{l}\text { rate per } 100 \\
\text { patient-yr }\end{array}$ \\
\hline Any adverse event & $577(95.1)$ & 262.3 & $1107(91.3)$ & 183.4 & $1562(90.5)$ & 159.8 & $3121(89.9)$ & 140.1 \\
\hline Severe adverse event $\dagger$ & $208(34.3)$ & 17.3 & $360(29.7)$ & 14.0 & $384(22.2)$ & 9.9 & $740(21.3)$ & 9.1 \\
\hline Serious adverse event $\dagger$ & 321 (52.9) & 31.7 & $552(45.5)$ & 24.9 & $667(38.6)$ & 19.6 & $1237(35.6)$ & 17.0 \\
\hline Death & $40(6.6)$ & 2.8 & $68(5.6)$ & 2.3 & $79(4.6)$ & 1.8 & $108(3.1)$ & 1.2 \\
\hline $\begin{array}{l}\text { Adverse event leading to } \\
\text { discontinuation }\end{array}$ & $167(27.5)$ & 12.6 & $278(22.9)$ & 10.0 & $286(16.6)$ & 6.9 & $535(15.4)$ & 6.2 \\
\hline \multicolumn{9}{|l|}{$\begin{array}{c}\text { Confirmed hypoglycemic } \\
\text { adverse event } t\end{array}$} \\
\hline Any & $233(38.4)$ & 22.9 & $391(32.3)$ & 17.9 & $417(24.2)$ & 11.7 & $912(26.3)$ & 12.8 \\
\hline Requiring assistance & $18(3.0)$ & 1.3 & $23(1.9)$ & 0.8 & $18(1.0)$ & 0.4 & $40(1.2)$ & 0.4 \\
\hline \multicolumn{9}{|l|}{$\begin{array}{l}\text { Event consistent with urinary } \\
\text { tract infection }\end{array}$} \\
\hline 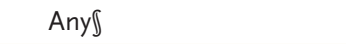 & $132(21.7)$ & 10.4 & $278(22.9)$ & 11.0 & 291 (16.9) & 7.5 & $564(16.2)$ & 6.9 \\
\hline Complicated & $17(2.8)$ & 1.2 & $37(3.1)$ & 1.3 & $24(1.4)$ & 0.6 & $45(1.3)$ & 0.5 \\
\hline $\begin{array}{l}\text { Event consistent with genital } \\
\text { infection } \|\end{array}$ & $10(1.6)$ & 0.7 & $64(5.3)$ & 2.2 & $32(1.9)$ & 0.7 & $237(6.8)$ & 2.7 \\
\hline $\begin{array}{l}\text { Event consistent with vol- } \\
\text { ume depletion } * * *\end{array}$ & $49(8.1)$ & 3.6 & $81(6.7)$ & 2.8 & $66(3.8)$ & 1.6 & $158(4.5)$ & 1.8 \\
\hline Acute renal failure $\dagger \dagger$ & $87(14.3)$ & 6.5 & $136(11.2)$ & 4.9 & $68(3.9)$ & 1.6 & $110(3.2)$ & 1.2 \\
\hline Acute kidney injury & $22(3.6)$ & 1.6 & $26(2.1)$ & 0.9 & $15(0.9)$ & 0.4 & $19(0.5)$ & 0.2 \\
\hline Diabetic ketoacidosistr & $1(0.2)$ & 0.1 & $2(0.2)$ & 0.1 & 0 & 0 & $2(0.1)$ & $<0.1$ \\
\hline Thromboembolic event $\int \mathbb{\int}$ & $7(1.2)$ & 0.5 & $13(1.1)$ & 0.4 & $13(0.8)$ & 0.3 & $17(0.5)$ & 0.2 \\
\hline Bone fracture $₫ 9$ & $32(5.3)$ & 2.3 & $57(4.7)$ & 2.0 & $59(3.4)$ & 1.4 & $122(3.5)$ & 1.4 \\
\hline Hyperkalemia\|\| & $42(6.9)$ & 3.0 & 47 (3.9) & 1.6 & $36(2.1)$ & 0.8 & $46(1.3)$ & 0.5 \\
\hline \multicolumn{9}{|c|}{$\begin{array}{l}\text { Data are for patients who received at least one dose of a study drug and include events that occurred during treatment or within } 7 \text { days } \\
\text { after the last receipt of a study drug. } \\
\text { A serious adverse event is defined as an event that is fatal or life-threatening, results in persistent or significant disability, requires or pro- } \\
\text { longs hospitalization, is associated with a congenital anomaly or birth defect, or is deemed to be serious for any other reason. A severe } \\
\text { adverse event is one that is incapacitating or that results in an inability to work or perform usual activities. } \\
\text { Hypoglycemia was defined as a plasma glucose level of } 70 \mathrm{mg} \text { per deciliter ( } 3.9 \mathrm{mmol} \text { per liter) or less or an event requiring assistance. } \\
\text { The definition of urinary tract infection was based on } 79 \text { preferred terms in the Medical Dictionary for Regulatory Activities (MedDRA). } \\
\text { Complicated urinary tract infection comprised pyelonephritis, urosepsis, and a serious adverse event consistent with urinary tract infection. }\end{array}$} \\
\hline
\end{tabular}

in the eGFR over time). Moreover, measures of even after long-term treatment. Most patients in renal function significantly improved after the this trial were receiving background RAAS discontinuation of empagliflozin, indicating that blockade, so the renal effects of empagliflozin glomerular hemodynamic changes were reversed were still apparent even with the use of these 
agents. This finding supports the potential use of empagliflozin in combination with RAAS blockers in patients with type 2 diabetes and chronic kidney disease. However, empagliflozin did not prevent incident albuminuria despite previous evidence that the drug lowers the intraglomerular pressure. ${ }^{20}$

The adverse-event profile of empagliflozin in patients who had impaired kidney function at baseline, a potentially vulnerable population, was consistent with that reported in the overall trial population. The proportion of patients with genital infection was greater in the empagliflozin group than in the placebo group, which was consistent with findings in previous studies. Rates of adverse events consistent with acute renal failure (including acute kidney injury) or hyperkalemia in the empagliflozin group were lower than or similar to those in the placebo group, regardless of whether patients had impaired kidney function at baseline.

In conclusion, among patients with type 2 diabetes who were at high risk for cardiovascular events, the use of empagliflozin was associated with slower progression of kidney disease than was placebo when added to standard care. Empagliflozin was also associated with a significantly lower risk of clinically relevant renal events.

Supported by the Boehringer Ingelheim and Eli Lilly and Company Diabetes Alliance.

Disclosure forms provided by the authors are available with the full text of this article at NEJM.org.

We thank all the patients who participated in this trial; and Elizabeth $\mathrm{Ng}$ and Wendy Morris of FleishmanHillard Fishburn for their medical writing assistance.

\section{REFERENCES}

1. The Emerging Risk Factors Collaboration. Diabetes mellitus, fasting blood glucose concentration, and risk of vascular disease: a collaborative meta-analysis of 102 prospective studies. Lancet 2010;375: 2215-22.

2. de Boer IH, Rue TC, Hall YN, Heagerty PJ, Weiss NS, Himmelfarb J. Tempo ral trends in the prevalence of diabetic kidney disease in the United States. JAMA 2011;305:2532-9.

3. Afkarian M, Sachs MC, Kestenbaum $B$, et al. Kidney disease and increased mortality risk in type 2 diabetes. J Am Soc Nephrol 2013;24:302-8.

4. UK Prospective Diabetes Study (UKPDS) Group. Intensive blood-glucose control with sulphonylureas or insulin compared with conventional treatment and risk of complications in patients with type 2 diabetes (UKPDS 33). Lancet 1998; 352:837-53.

5. Coca SG, Ismail-Beigi F, Haq N, Krumholz HM, Parikh CR. Role of intensive glucose control in development of renal end points in type 2 diabetes mellitus: systematic review and meta-analysis intensive glucose control in type 2 diabetes. Arch Intern Med 2012;172:761-9.

6. The ADVANCE Collaborative Group. Intensive blood glucose control and vascular outcomes in patients with type 2 diabetes. N Engl J Med 2008;358:256072.

7. Perkovic V, Heerspink HL, Chalmers J, et al. Intensive glucose control improves kidney outcomes in patients with type 2 diabetes. Kidney Int 2013;83:517-23.

8. Zoungas S, Chalmers J, Neal B, et al. Follow-up of blood-pressure lowering and glucose control in type 2 diabetes. N Engl J Med 2014;371:1392-406.

9. Roscioni SS, Heerspink HJ, de Zeeuw D. The effect of RAAS blockade on the progression of diabetic nephropathy. Nat Rev Nephrol 2014;10:77-87.

10. Molitch ME, Adler AI, Flyvbjerg A, et al. Diabetic kidney disease: a clinical update from Kidney Disease: Improving Global Outcomes. Kidney Int 2015;87:2030 .

11. Heise T, Seewaldt-Becker E, Macha S, et al. Safety, tolerability, pharmacokinetics and pharmacodynamics following 4 weeks' treatment with empagliflozin once daily in patients with type 2 diabetes. Diabetes Obes Metab 2013;15:613-21.

12. Häring HU, Merker L, Seewaldt-Becker E, et al. Empagliflozin as add-on to metformin plus sulfonylurea in patients with type 2 diabetes: a 24-week, randomized, double-blind, placebo-controlled trial. Diabetes Care 2013;36:3396-404.

13. Häring HU, Merker L, Seewaldt-Becker E, et al. Empagliflozin as add-on to metformin in patients with type 2 diabetes: a 24-week, randomized, double-blind, placebo-controlled trial. Diabetes Care 2014;37:1650-9.

14. Kovacs CS, Seshiah V, Swallow R, et al. Empagliflozin improves glycaemic and weight control as add-on therapy to pioglitazone or pioglitazone plus metformin in patients with type 2 diabetes: a 24-week, randomized, placebo-controlled trial. Diabetes Obes Metab 2014;16:147-58.

15. Roden M, Weng J, Eilbracht J, et al. Empagliflozin monotherapy with sitagliptin as an active comparator in patients with type 2 diabetes: a randomised, doubleblind, placebo-controlled, phase 3 trial. Lancet Diabetes Endocrinol 2013;1:208-19. 16. Rosenstock J, Jelaska A, Frappin G, et al. Improved glucose control with weight loss, lower insulin doses, and no increased hypoglycemia with empagliflozin added to titrated multiple daily injections of insulin in obese inadequately con- trolled type 2 diabetes. Diabetes Care 2014;37:1815-23.

17. Rosenstock J, Jelaska A, Zeller C, Kim G, Broedl UC, Woerle HJ. Impact of empagliflozin added on to basal insulin in type 2 diabetes inadequately controlled on basal insulin: a 78-week randomized, doubleblind, placebo-controlled trial. Diabetes Obes Metab 2015;17:936-48.

18. Tikkanen I, Narko K, Zeller C, et al. Empagliflozin reduces blood pressure in patients with type 2 diabetes and hypertension. Diabetes Care 2015;38:420-8.

19. Barnett AH, Mithal A, Manassie J, et al. Efficacy and safety of empagliflozin added to existing antidiabetes treatment in patients with type 2 diabetes and chronic kidney disease: a randomised, doubleblind, placebo-controlled trial. Lancet Diabetes Endocrinol 2014;2:369-84.

20. Skrtić M, Yang GK, Perkins BA, et al. Characterisation of glomerular haemodynamic responses to SGLT2 inhibition in patients with type 1 diabetes and renal hyperfiltration. Diabetologia 2014;57:2599602.

21. Cherney DZ, Perkins BA, Soleymanlou N, et al. Renal hemodynamic effect of sodium-glucose cotransporter 2 inhibition in patients with type 1 diabetes mellitus. Circulation 2014;129:587-97.

22. Škrtić M, Cherney DZ. Sodium-glucose cotransporter-2 inhibition and the potential for renal protection in diabetic nephropathy. Curr Opin Nephrol Hypertens 2015;24:96-103.

23. Zinman B, Wanner C, Lachin JM, et al. Empagliflozin, cardiovascular outcomes, and mortality in type 2 diabetes. $\mathrm{N}$ Engl J Med 2015;373:2117-28.

24. Zinman B, Inzucchi SE, Lachin JM, et al. Rationale, design, and baseline characteristics of a randomized, placebo-controlled cardiovascular outcome trial of 
empagliflozin (EMPA-REG OUTCOME). Cardiovasc Diabetol 2014;13:102.

25. Levey AS, Bosch JP, Lewis JB, Greene $\mathrm{T}$, Rogers N, Roth D. A more accurate method to estimate glomerular filtration rate from serum creatinine: a new prediction equation. Ann Intern Med 1999;130: 461-70.

26. Levey AS, Stevens LA, Schmid CH, et al. A new equation to estimate glomerular filtration rate. Ann Intern Med 2009;150: 604-12.

27. Gaede P, Vedel P, Larsen N, Jensen GV, Parving HH, Pedersen O. Multifactorial intervention and cardiovascular disease in patients with type 2 diabetes. $\mathrm{N}$ Engl J Med 2003;348:383-93.

28. Chilton R, Tikkanen I, Cannon CP, et al. Effects of empagliflozin on blood pressure and markers of arterial stiffness and vascular resistance in patients with type 2 diabetes. Diabetes Obes Metab 2015;17:1180-93.

29. Cherney DZ, Perkins BA, Soleymanlou $\mathrm{N}$, et al. The effect of empagliflozin on arterial stiffness and heart rate variability in subjects with uncomplicated type 1 diabetes mellitus. Cardiovasc Diabetol 2014;13:28.
30. Vallon V, Gerasimova M, Rose MA, et al. SGLT2 inhibitor empagliflozin reduces renal growth and albuminuria in proportion to hyperglycemia and prevents glomerular hyperfiltration in diabetic Akita mice. Am J Physiol Renal Physiol 2014; 306:F194-204.

31. Cherney DZ, Perkins BA, Soleymanlou N, et al. Sodium glucose cotransport-2 inhibition and intrarenal RAS activity in people with type 1 diabetes. Kidney Int 2014;86:1057-8.

32. Jordan J, Tank J, Heusser K, et al. Empagliflozin has no discernable effect on muscle sympathetic nerve activity in patients with type 2 diabetes despite reductions in blood pressure and weight. Diabetes 2014;63:Suppl 1:A265 (poster).

33. Lewis EJ, Hunsicker LG, Clarke WR, et al. Renoprotective effect of the angiotensin-receptor antagonist irbesartan in patients with nephropathy due to type 2 diabetes. N Engl J Med 2001;345:85160.

34. Brenner BM, Cooper ME, de Zeeuw D, et al. Effects of losartan on renal and cardiovascular outcomes in patients with type 2 diabetes and nephropathy. $\mathrm{N}$ Engl J Med 2001;345:861-9.
35. Parving H-H, Brenner BM, McMurray JJV, et al. Cardiorenal end points in a trial of aliskiren for type 2 diabetes. $\mathrm{N}$ Engl J Med 2012;367:2204-13.

36. Brown NJ, Vaughan DE. Angiotensinconverting enzyme inhibitors. Circulation 1998;97:1411-20.

37. Kobori $\mathrm{H}$, Nangaku M, Navar LG, Nishiyama A. The intrarenal renin-angiotensin system: from physiology to the pathobiology of hypertension and kidney disease. Pharmacol Rev 2007;59:25187.

38. Schoolwerth AC, Sica DA, Ballermann BJ, Wilcox CS. Renal considerations in angiotensin converting enzyme inhibitor therapy: a statement for healthcare professionals from the Council on the Kidney in Cardiovascular Disease and the Council for High Blood Pressure Research of the American Heart Association. Circulation 2001;104:1985-91.

39. Holtkamp FA, de Zeeuw D, Thomas $\mathrm{MC}$, et al. An acute fall in estimated glomerular filtration rate during treatment with losartan predicts a slower decrease in long-term renal function. Kidney Int 2011;80:282-7.

Coppright $\odot 2016$ Massachusetts Medical Society. in a public trials registry. The members of the International Committee of Medical Journal Editors (ICMJE) will consider most reports of clinical

trials for publication only if the trials have been registered.

Current information on requirements and appropriate registries is available at www.icmje.org/faq_clinical.html. 